\title{
A Rapid, Accurate and Easy Method for Determination of Trace Elements in Lubricating Oil Using ICP-OES
}

\author{
Hersh J. Noori", Azad H. Alshatteri ${ }^{*}$ and Nabil A. Fakhre**
}

* Department of Chemistry, College of Education, Garmian University- Kalar, Sulaimani

*** Department of Chemistry, College of Education, Salahaddin University- Erbil)

hersh.jalil@garmian.edu.krd

\begin{abstract}
A procedure of extraction by emulsion breaking (EIEB) was developed for determination of trace elements in 10 different lubrication oil samples. It was based on the preparation of an emulsion followed by breaking the emulsion by centrifugation. The aqueous phase was extracted and collected for determination the trace elements using inductive coupled plasma - optical emission spectroscopy. The chemical and physical variables influencing the extraction were optimized. The LODs obtained were ranged from $1.2 \mu \mathrm{g} \mathrm{L}^{-1}$ to $5.8 \mu \mathrm{g} \mathrm{L}^{-1}$. The RSDs ranged from $1.1 \%$ to $6.7 \%$. EIEB was suitable for determination of the analytes at $\mu \mathrm{g}$ L-1 levels in lubricants samples collected from several markets in Kalar and Sulaimani Cities.
\end{abstract}

KeyWords: Trace elements, extraction by emulsion, lubricating oil and ICP-OES.

\section{Introduction:}

Lubricating oils produced from crude oil. The major composition lubrication oil is paraffinic, naphthenic and the minor component is aromatic hydrocarbons. Commercial lubricating oil contains several type of additives in the form of organometallic to improve the oil performance as part of final compositions[1]. Lubricating oil has an essential role in several sectors approximating in the lubrication of engine of cars, vehicles, buses and more and used in hydraulic system industry, stationary engines, turbines, and extra. Its value is to protect the movable parts, reducing friction and cleaning inside of the engines[2].

A respectable method to evaluate the condition of lubricating oils is the determination of the concentration of metals, which helps to identify the unnecessary wear of the engine. The wearing of metals causes such as solid metal remains of different size, metal oxides, and metallorganic species, from mechanical wear, oxidative corrosion and chemical corrosion, respectively.[3] 
Sensitive techniques are required for determination of trace elements in lubricating oils. The most common pre-treatment employed in the analysis of lubricating oils depended on (i) ashing technique in the form of dry ashing[4-5], wet and modify wet ashing[6](ii) Acid digestion of the sample, mixed solvent extraction, ultrasonic extraction and stripping[7-8]. (iii) Direct dilution of oil sample with an appropriate organic solvent[9-10]. (iv) Conversion of the sample into oil-in-water emulsions and micro-emulsions[5-11]. The ashing and direct dilution of the sample are enormously times consumed. Although because ashing technique is very easy and cheap, but it has a considerable risk of sample contamination and analyte loss as volatile species in addition to its requirement to a high temperature furnace with 5-8 hours thus very slow procedure. As similar to ashing procedure in acid digestion, organic matrix mineralized and the total metal content converted to simple water-soluble species.

However, the dilution with organic solvents is an easy and fast procedure, but then again for lubricating oils are not recommended because of difficulties concerning repeatability and false results owing to the presence of insoluble solid inorganic species arising from physical wear. It also requires the use of organometallic standards increasing analysis costs[12].

The alternative more frequent is emulsification. Emulsification seems to solve the problem of sample preparation for several petrochemical products. The non-miscible system waterorganic liquid by the formation of emulsions and micro-emulsions, using anionic, non-ionic and amphoteric surfactants does not require a previous mineralization. Moreover, emulsification uses as simple and fast sample preparation procedure. Usually, when emulsion or micro-emulsion sample preparation approves the determination is possible using calibration with aqueous solutions instead of the organometallic standards. When the oil is homogeneously dispersed in the water phase, the sample behaves similarly to an aqueous solution[13].

Several instrumental techniques have been described in the literature for determination of trace elements in lubricating oil. Among them, flame atomic absorption spectrometry (FAAS) has been one of the most commonly used techniques in the analysis of lubricating oils[7-9]; graphite furnace atomic absorption spectrometry (GF-AAS); electro thermal atomic absorption spectroscopy (ET-AAS)[11, 12, 14]; inductively coupled plasma optical emission spectrometry (ICP-OES)[9, 10, 15-17], and inductively coupled plasma mass spectrometry (ICP-MS)[18].

Recently, a new sample protocol appeared, named extraction induced by emulsion breaking, for the extraction of metals from oil samples. This method is be governed by the formation 
and breaking of detergent emulsions. It is prepared by mixing the oil samples with acid aqueous solutions. During emulsion breaking, which induced by heating or centrifugation, the analytes are transferred to the aqueous phase that is separated from the oil. The method can successfully applied in the determination of trace concentration of various metals in different types of oils.

\section{Experimental:}

\subsection{Instrumentation:}

For this study, an inductive coupled plasma optical emission spectrometer (Spectro Arcos model Germany) with RF generator of $27.12 \mathrm{MHz}$ was employed. The analytical emission line used in the study were by $(\mathrm{nm})(\mathrm{Be}) 313.042$, (Ce) 418.660, $(\mathrm{Cu}) 324.754,(\mathrm{Fe})$ 259.941, (K) 766.491, (Li) 670.780, (Mn) 257.611, (Mo) 202.095, (Na) 589.592, (Ni) 231.604, (Ca) 396.847, (V) 292.464, (Sr) 339.198, (Tl) 334.941, (Zn) 213.656, (Pb) 220.353, (Cd) 214.438, (As) 189.042, (Cr) 267.716, (Si) 251.612.

The broken emulsion was performed by centrifugation using a centrifuge universal $320 \mathrm{R}$ model (Hittch- Germany). Which operated at a maximum rotation speed of $3000 \mathrm{rpm}$ and 30 minutes.

\subsection{Reagent and solutions:}

All reagents employed were of analytical grade. Deionized water (Germany) used to prepare all aqueous solutions. Nitric acid (Merck, Germany), a non-ionic surfactant (Triton X100) were Merck (Germany). Isobutyl methyl ketone from Sigma-Aldrich (Germany). The analytical multi-standard solution from Bernd Kraft - Der standard (Germany) with different analytical concentrations.

\subsection{Procedure:}

The elements extracted from crude oil sample through the extraction induced by emulsion breaking (EIEB). The procedure is based on the formation a stable emulsions between the samples and an acid Triton X-100. To improving the extraction of the metals, in the initial, $80 \%$ of the samples (approximately $5.2 \mathrm{~g}$ ) and $20 \%$ of the $3 \%$ acidic Triton X-100 solution were mixed, and stable water-in-oil emulsions were obtaining by vigorous mixing of the samples. The emulsions were agitated for 30 minutes on a mixer (auto vortex). To promote the emulsion breaking the mixed solution was putting in the centrifuge at 3000 RPM for 30 minutes. The emulsion breaking resulted in two well-separated phases: an upper phase containing the organic part of the solution and a lower phase containing the aqueous acid 
solution with the extracted elements. At that moment, the upper phase was removed and the lower aqueous phase was collected and transferred the calibrated flasks then diluted to the mark with deionized water. Finally, the solution was used to measure the elements of interest.

\section{Results and Discussion:}

In this study, initially the trace elements determined as preliminary investigation for S2 lubricating oil sample by ICP-OES as shown in table (3.2). Then the optimization of the method has done by studying the influence of some variables such as: (a) category and volume of the solvent engaged to dilute the samples, (b) the concentrations of Triton X-100 and $\mathrm{HNO}_{3}$ in the solution used for emulsification and (c) extraction conditions. In all experimentations, normalized signals of $\mathrm{Na}^{+}, \mathrm{K}^{+}$and $\mathrm{Ca}^{2+}$ were used to evaluate the results the highest emission signal obtained.

\subsection{Evaluation of the type and concentration of solvent:}

Initially, the sample was mixed with the emulsifier agent without using dilution by any solvent. A viscos solution was obtained then so after emulsion breaking give us a minimum aqueous phase and highly turbidity. To solve the problem organic solvents were used for dilution. The investigation was performed using four solvents in which the lubricating oils were highly soluble: toluene, IBMK, xylene and hexane. The volumetric proportion of solvent was kept constant at $10 \% \mathrm{v} / \mathrm{v}$ and the extraction efficiency was evaluated. There was no significant difference among the signals obtained when the sample was diluted with xylene and toluene and hexane gave the minimum analytical signal. While using of IBMK resulted in separation of an aqueous phase with lowest turbidity and gave highest analytical signal as shown fig. (3.2). which indicate the lowest transfer of organic materials to the aqueous phase. Therefore, it was employed for dilution of the samples.

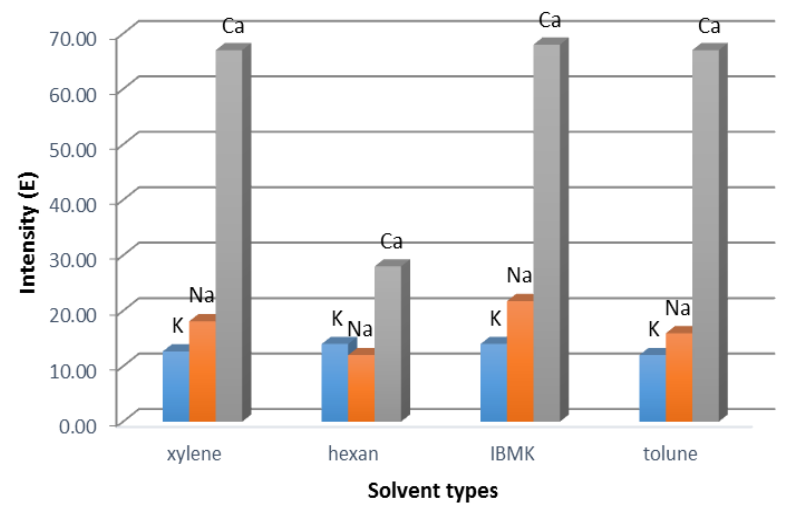

Figure 3.1: Effect of the solvent employed to decrease the viscosity of the oil on the extraction of $\mathrm{Na}^{+}, \mathrm{K}^{+}$and $\mathrm{Ca}^{2+}$ ions.

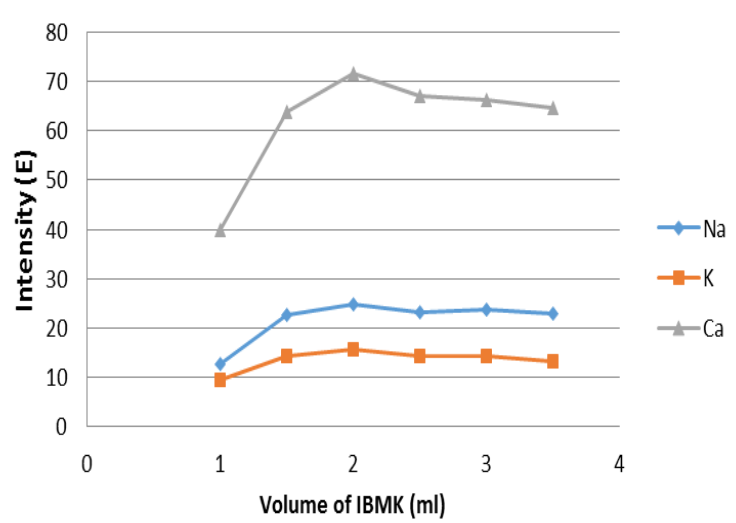

Figure 3.2: Effect of the IBMK volume to decrease the viscosity of the oil on the extraction of $\mathrm{Na}^{+}, \mathrm{K}^{+}$ and $\mathrm{Ca}^{2+}$ ions 
The effect of the volume of IBMK was studied. Figure (3.2) shows that the analytical signal decreases with the increasing of the proportion of solvent because the dilution factor increased with the increase of the amount of solvent employed. In addition to, emulsion stability increases with increasing the volume of the solvent, thus breaking of the emulsion is too difficult. A proportion of $20 \% \mathrm{v} / \mathrm{v}$ was chosen, in order to avoid excessive dilution of the samples and make the collection of the aqueous phase easier.

\subsection{Effect of the concentration of Triton X-100:}

The most important parameter studied in the optimization of the proposed methodology was the effect of the concentration of Triton X-100 used for emulsification. The study was achieved by changing the Triton X-100 concentration in the range of $1-8 \% \mathrm{v} / \mathrm{v}$ as shown in figure (3.3). It is important to note that the emulsification was always carried out by vigorous mixing of $6.0 \mathrm{~mL}$ of lubricating oil and $2 \mathrm{~mL}$ IBMK with $2 \mathrm{~mL}$ of the acidified Triton X-100.

The most evident effect of Triton X-100 concentration on the extraction process was the variation of the volume of aqueous phase recovered after the emulsion breaking. The volume of aqueous phase separated after the emulsion breaking decreased with the increase of the surfactant concentration.

Once the emulsion was formed, it was agitated for 30 minutes on the auto vortex mixer to extract the analytes and centrifuged for $30 \mathrm{~min}$ for emulsion breaking. Then, the aqueous phase was collected, approximately diluted 25 times with distilled water.

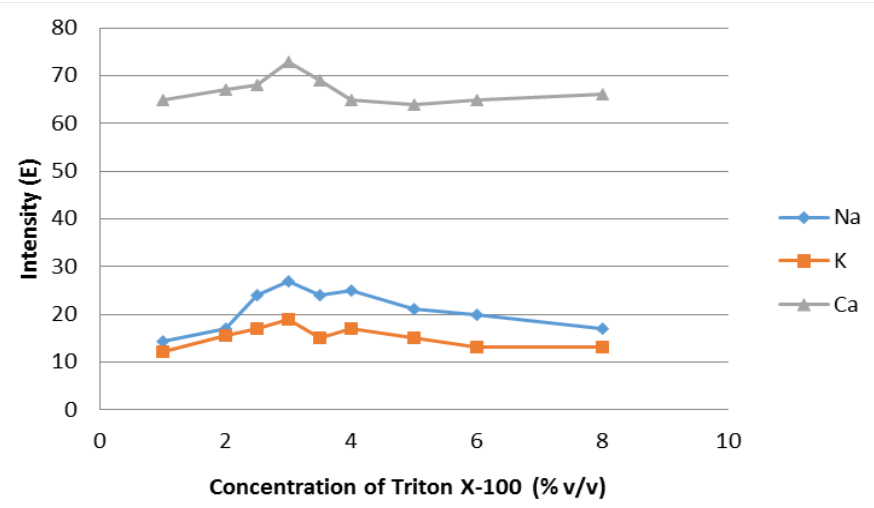

Figure 3.3: Effect of the conc. of Triton $\mathrm{X}-100$ on the extraction of $\mathrm{Na}^{+}, \mathrm{K}^{+}$and $\mathrm{Ca}^{2+}$ ions.

The analytical signals were used to choosing best concentration. Although the mean signals obtained with the concentrations of $3 \% \mathrm{v} / \mathrm{v}$ were slightly higher. Therefore, the concentration of $3 \% \mathrm{v} / \mathrm{v}$ of Triton X-100 was selected to achieve the highest extraction efficiency and easy to break. 


\subsection{The Effect of HNO3 Concentration:}

The concentration of $\mathrm{HNO}_{3}$ to form the emulsion plays an important role in the proposed methodology, as the acid is responsible for the extraction of the analytes from the lubricating oil, where they are present as organometallic molecules or organic complexes, into the aqueous phase. The $\left(\mathrm{H}^{+}\right.$ion) is responsible for the extraction, displacing the metallic cations from the organic structures where they are in the oils. The concentration of Triton X100 was maintained at $3 \% \mathrm{v} / \mathrm{v}$ and an extraction time of $30 \mathrm{~min}$ was employed. In order to evaluate the effect of this variable, the concentration of $\mathrm{HNO}_{3}$ in the extracting solution was varied in the range of $1-5$ mole $\mathrm{L}^{-1}$.

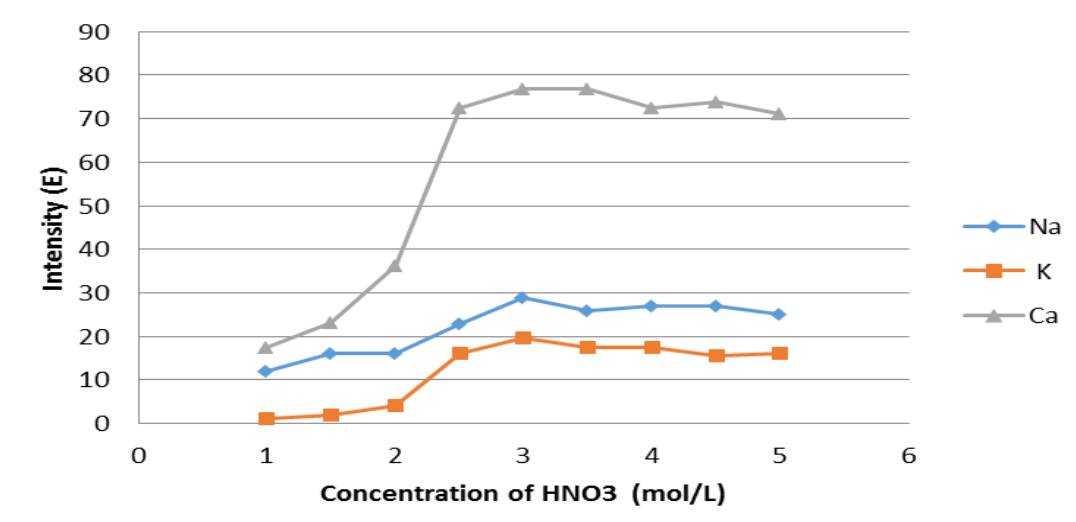

Figure 3.4: Effect of the $\mathrm{HNO}_{3}$ conc. on the extraction of $\mathrm{Na}^{+}, \mathrm{K}^{+}$and $\mathrm{Ca}^{2+}$ ions.

As shown in fig. (3.5) the extraction efficiency increases with the increasing $\mathrm{HNO}_{3}$ concentration. For $\mathrm{Na}, \mathrm{K}$ and $\mathrm{Ca}$ ions, the extraction increased up to a $2.5 \mathrm{~mol} \mathrm{~L}^{-1}$, after this point, the extraction efficiency approximately remained almost constant. Thus, the $\mathrm{HNO}_{3}$ concentration of (3.0 mole $\mathrm{L}^{-1)}$ was chosen in the subsequent experiments.

\subsection{The Effect of the Volume of Acidic Triton X-100}

After choosing the concentration of both Triton $\mathrm{X}-100$ and $\mathrm{HNO}_{3}$, another parameter was the effect volume of acidic Triton X-100. With increasing the volume of acidic Triton X100 the volume of aqueous phase was increased. Thus breaking of the emulsion became easier. In order to evaluate the effect of this variable, the various volumes $(1.0-6.0 \mathrm{ml})$ were used as shown in fig. (3.5). A proportion of $(2.0 \mathrm{ml})$ was selected for the method. 


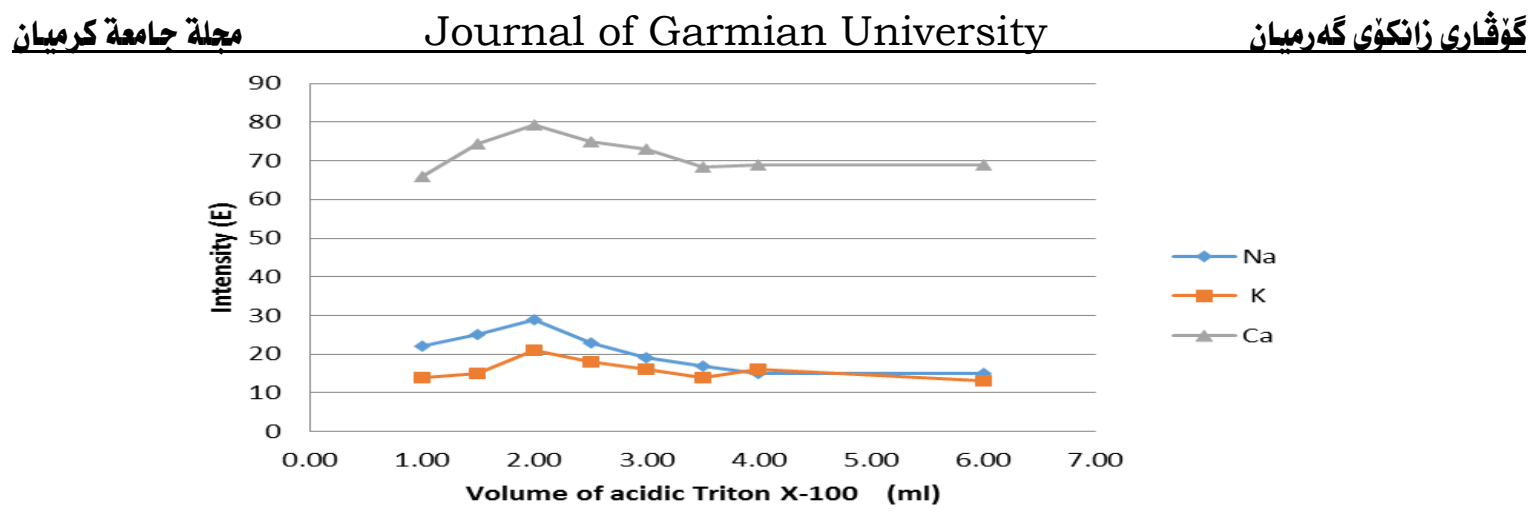

Figure 3.5: Effect of the volume of the acidic Triton $\mathrm{X}-100$ on the extraction of $\mathrm{Na}^{+}, \mathrm{K}^{+}$and $\mathrm{Ca}^{2+}$.

\subsection{Evaluation of the extraction time}

The proposed method was based on the acid extraction of the elements from the oil to the aqueous phase. Although the formation of water-in-oil emulsions makes the extraction more effective, due to the more intense penetration of the aqueous acid solution in the oil sample, sometime time can be required to promote total leaching of the analytes from the organic phase, especially at normal temperature. Therefore, the effect of the extraction time was studied. Extraction time was considered as the time elapsed between the emulsion formation and the beginning of the centrifugation for breaking. The extraction was carried out keeping the emulsions under continuous agitation on an auto vortex, during periods of time that varied in the range of 5-60 min. The results obtained are shown in Figure (3.6).

Maximum extraction was acquired when the extraction time was 20 to $35 \mathrm{~min}$. with high emission value of $\mathrm{Ca}^{2+}$ ions. This behaviour reinforces the idea raised previously that both elements $\mathrm{K}^{+}$and $\mathrm{Na}^{+}$are bonded to the organic molecules present in the oil through more stable interactions, which are slow to cleave in the presence of acid to produce hydrophilic species, when compared to the $\mathrm{Ca}^{2+}$ ion. Thus according to the results obtained, an extraction time of 30 min was chosen in the subsequent experiments in order to ensure the extraction of all analytes under study.

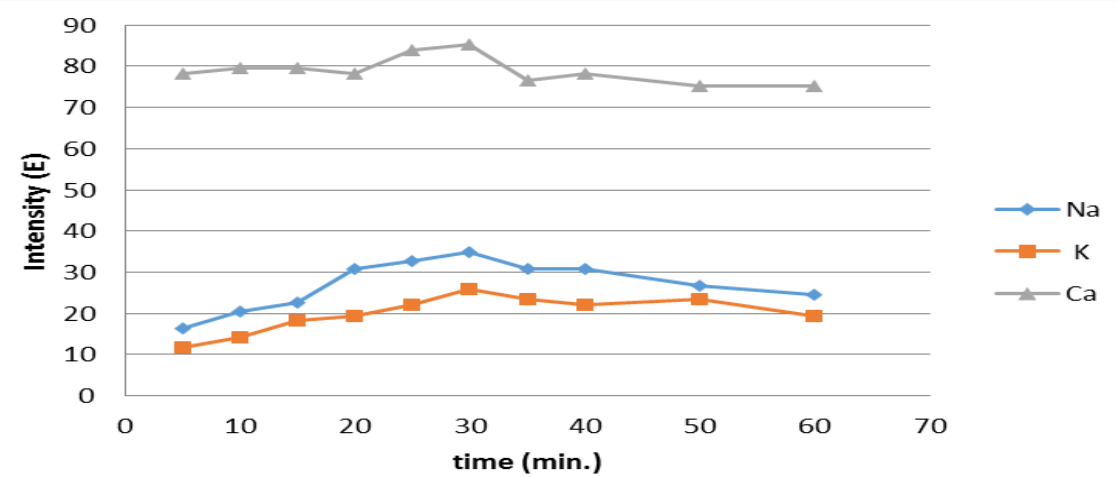

Figure 3.6: Effect of extraction time on the extraction of $\mathrm{Na}^{+}, \mathrm{K}^{+}$and $\mathrm{Ca}^{2+}$ ions. 


\subsection{Centrifugation times:}

One of the main concerns in this study was related to the establishment of the centrifugation conditions, which was responsible for the emulsion breaking. In the previous experiments, the centrifugation of the emulsions was always carried out for $60 \mathrm{~min}$ at 3500 rpm. Therefore, in order to evaluate the influence of the centrifugation time on the phase separation, the emulsion breaking was performed at different centrifugation times, always keeping the rotation at $3500 \mathrm{rpm}$. The centrifugation time was changed in the range of 10-60 min and a convenient separation of the phases was observed 20-35min (fig. 3.7). For times lower than $15 \mathrm{~min}$, the emulsions were not completely broken, since residual amounts of the emulsions remained in the interface between the oil and the aqueous phase. In addition, in these cases, the volume of aqueous phase recovered was always lower than $1.5 \mathrm{~mL}$, evidencing that a noticeable part of the aqueous phase remained emulsified with the lubricating oil.

Additionally, the effect of the centrifugation time was also tested in relation to the analytical signal for $\mathrm{Na}^{+}, \mathrm{K}^{+}$and $\mathrm{Ca}^{2+}$. Therefore, a centrifugation time of $25 \mathrm{~min}$. was selected for the method in order to make it faster.

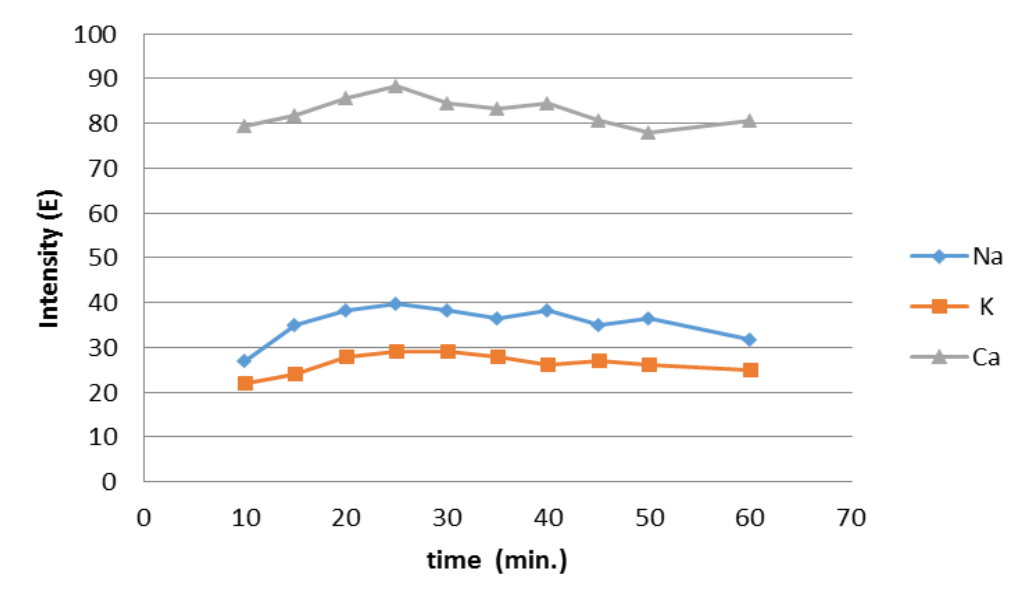

Figure 3.7: Effect of centrifugations time on the extraction of $\mathrm{Na}^{+}, \mathrm{K}^{+}$and $\mathrm{Ca}^{2+}$ ions.

\subsection{Study of centrifugation speed:}

The final and one of the main concerns in this study was related to the establishment of the centrifugation conditions, which was responsible for the emulsion breaking. In the previous experiments, the centrifugation speeds of the emulsions were always carried out at $3500 \mathrm{rpm}$. In order to evaluate the influence of the centrifugation speed on the phase 
separation, the emulsion breaking was performed at different centrifugation speed. The centrifugation speed were changed in the range of 1000-6000 RPM (figure 3.8) and the convenient separation of the phases was observed with a minimum time of 30 minutes (figure $3.8)$.

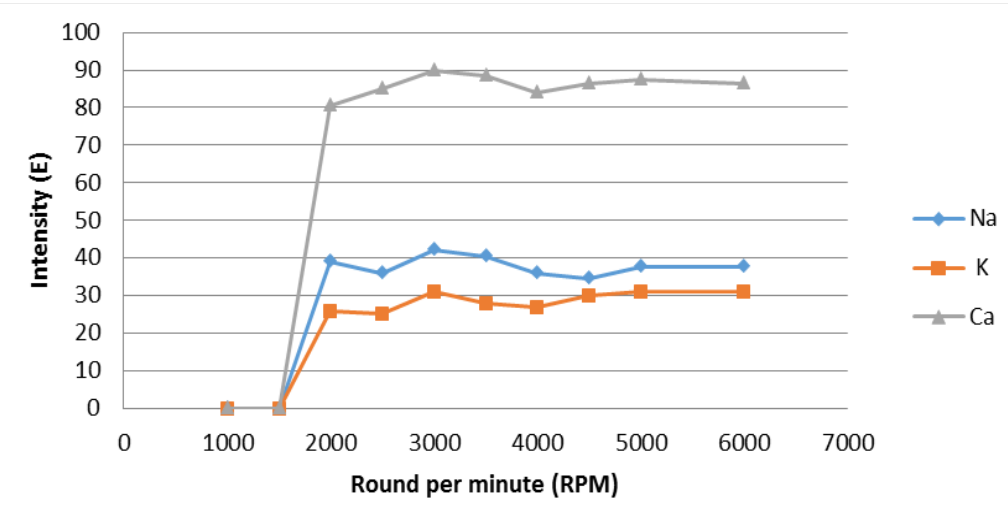

Figure 3.8: Effect of centrifugations speed to extraction of $\mathrm{Na}^{+}, \mathrm{K}^{+}$and $\mathrm{Ca}^{2+}$ ions

By using 1000-1500 rpm, the emulsions were not completely broken, since residual amounts of the emulsions remained in the interface between the oil and aqueous phase. In addition, a high turbid aqueous phase recovered was always less than $1.5 \mathrm{~mL}$, above $2500-6000 \mathrm{rpm}$ the signals are relatively equal only at $3000 \mathrm{rpm}$ the analytical signal are slightly higher, Therefore, a centrifugation speed at $3000 \mathrm{rpm}$ was selected for the extraction.

\subsection{Determination of trace elements in lubricating oil samples by the developed methodology}

The proposed procedure has been used for extraction and determination of the trace elements in different lubricating oil samples were analysed by the proposed methodology after complete optimization (table 3.1). The trace elements were determined in same lubricating oil samples for the second times as shown in the table (3.2). the results showed that the EIEB is sensitive, simple and cheap. Thus it was applied for determination of trace elements in 10 different oil samples using ICP-OES techniques the results shown in the tables (3.3).

Table 3.1 Results of EIEB optimization conditions

\begin{tabular}{|l|l|}
\hline Subjects & Result \\
\hline Study best type of solvents & IBMK \\
\hline Study of best volume of IBMK & $2.0 \mathrm{~mL}$ \\
\hline Study of conc. of acidic Triton X-100 & $3 \% \mathrm{v} / \mathrm{v}$ \\
\hline Study of conc. of $\mathrm{HNO}_{3}$ & $3.0 \mathrm{~mol} . \mathrm{L}^{-1}$ \\
\hline Study of volume of acidic Triton X-100 & $2.0 \mathrm{~mL}$ \\
\hline Study of shaking time & $25 \mathrm{minutes}$ \\
\hline Study of centrifugations times & 25 minutes \\
\hline Study of centrifugations speed & $3000 \mathrm{RPM}$ \\
\hline
\end{tabular}


Table 3.2: Conc. and RSD of trace elements before and after optimization by using ICP-OES.

\begin{tabular}{|c|c|c|c|c|}
\hline EIEB & \multicolumn{2}{|c|}{ Before optimization } & \multicolumn{2}{c|}{ After optimization } \\
\hline Element & Conc. $\left(\mu \mathrm{g} . \mathrm{L}^{-1}\right)$ & RSD $\%$ & Conc. $\left(\mu \mathrm{g} . \mathrm{L}^{-1}\right)$ & 0.67 \\
\hline $\mathbf{N a}$ & 50218 & 1.02 & 63621 & 0.98 \\
\hline $\mathbf{K}$ & 33710 & 1.31 & 35710 & 6.02 \\
\hline $\mathbf{C a}$ & 257648 & 5.58 & 345684 & 0.25 \\
\hline $\mathbf{N i}$ & 5900 & 2.01 & 6547 & 3.24 \\
\hline $\mathbf{F e}$ & 7300 & 4.61 & 8540 & 2.01 \\
\hline $\mathbf{C u}$ & 410 & 3.74 & 487 & 0.21 \\
\hline $\mathbf{Z n}$ & 470 & 0.84 & 590 & 4 \\
\hline $\mathbf{P b}$ & 574 & 4.26 & 864 & 7.05 \\
\hline $\mathbf{M g}$ & 1450 & 5.04 & 1550 & 0.16 \\
\hline $\mathbf{C d}$ & 387 & 0.64 & 428 & \\
\hline
\end{tabular}

Table 3.1: Concentration of trace elements in lubricating oil by ICP-OES in mg/L

\begin{tabular}{|c|c|c|c|c|c|c|c|c|c|c|}
\hline ICP & S1 & $\mathrm{S} 2$ & S3 & S4 & S5 & S6 & S7 & S8 & S9 & S10 \\
\hline $\mathrm{Ca}$ & 379.8 & 354.2 & 778.3 & 1447.2 & 2084.0 & 1572.2 & 849.4 & 1445.4 & 1562.1 & 1084.3 \\
\hline $\mathrm{Be}$ & 0.2 & 0.1 & 0.1 & 0.2 & 0.2 & 0.1 & 0.3 & 0.2 & 0.1 & 0.3 \\
\hline $\mathrm{Mn}$ & 0.1 & $<\mathrm{DL}$ & 0.2 & $<\mathrm{DL}$ & 0.2 & $<\mathrm{DL}$ & $<\mathrm{DL}$ & $<\mathrm{DL}$ & $<\mathrm{DL}$ & $<\mathrm{DL}$ \\
\hline $\mathrm{Na}$ & 108.1 & 67.1 & 63.7 & 212.3 & 174.4 & 123.5 & 310.2 & 179.6 & 159.9 & 397.6 \\
\hline K & 34.1 & 36.0 & 28.1 & $<\mathrm{DL}$ & 74.8 & 27.5 & $<\mathrm{DL}$ & 19.1 & 44.8 & $<\mathrm{DL}$ \\
\hline $\mathrm{Ni}$ & 8.0 & 6.35 & 6.2 & 5.4 & 7.1 & 4.9 & 6.2 & 6.2 & 6.5 & 6.5 \\
\hline $\mathrm{Sr}$ & 1.2 & 1.0 & 0.7 & $<\mathrm{DL}$ & 0.7 & $<\mathrm{DL}$ & $<\mathrm{DL}$ & $<\mathrm{DL}$ & $<\mathrm{DL}$ & $<\mathrm{DL}$ \\
\hline $\mathrm{Fe}$ & 7.6 & 8.6 & 13.3 & 38.8 & 28.9 & 4.2 & $<\mathrm{DL}$ & $<\mathrm{DL}$ & 34.5 & $<\mathrm{DL}$ \\
\hline $\mathrm{Cu}$ & $<\mathrm{DL}$ & 0.5 & $<\mathrm{DL}$ & $<\mathrm{DL}$ & $<\mathrm{DL}$ & $<\mathrm{DL}$ & $<\mathrm{DL}$ & $<\mathrm{DL}$ & $<\mathrm{DL}$ & $<\mathrm{DL}$ \\
\hline $\mathrm{Si}$ & 18.1 & 14.3 & 19.2 & 29.9 & 25.6 & 13.7 & 39.9 & 17.1 & 22.8 & 33.3 \\
\hline $\mathrm{Tl}$ & 1.9 & 1.4 & 1.2 & 2.4 & 1.7 & 1.1 & 3.4 & 1.2 & 1.0 & 2.5 \\
\hline V & 7.6 & 6.5 & 6.5 & 5.0 & 6.4 & 5.0 & 6.1 & 5.3 & 6.7 & 6.3 \\
\hline Mo & 2.4 & 42.2 & 2.6 & 0.7 & 2.0 & $<\mathrm{DL}$ & 0.8 & 3.4 & $<\mathrm{DL}$ & 0.5 \\
\hline $\mathrm{Zn}$ & 70.0 & 0.62 & $<\mathrm{DL}$ & 6.2 & $<\mathrm{DL}$ & 20.4 & 35.2 & $<\mathrm{DL}$ & $<\mathrm{DL}$ & 62.4 \\
\hline $\mathrm{Cd}$ & $<\mathrm{DL}$ & 0.4 & 0.4 & $<\mathrm{DL}$ & 0.0 & $<\mathrm{DL}$ & $<\mathrm{DL}$ & $<\mathrm{DL}$ & 0.0 & $<\mathrm{DL}$ \\
\hline $\mathrm{Pb}$ & 0.3 & 0.91 & 1.7 & 0.5 & 0.8 & 0.4 & 0.9 & 0.4 & 1.6 & $<\mathrm{DL}$ \\
\hline As & 2.5 & 3.4 & 2.2 & 2.9 & 2.9 & 2.7 & 3.6 & 2.9 & 3.3 & 2.6 \\
\hline
\end{tabular}

\section{Conclusion:}

Sample preparation is a critical stage in the oil analysis. The procedure required pretreatment of the samples to destroy the organic matrix involving certain manipulations and subsequent risk of sample contamination and/or analyte loss. 
The results obtained proved that the EIEB procedures are sensitive, simple and cheap method also, it is useful for routine analysis and it can be considered as a good alternative than DA and WA procedures. EIEB procedure avoids laborious and time-consuming digestion of the samples. It was carried out by simply formation of stable water-in-oil emulsions of lubricating oil, which was always achieved by vigorous mixing of sample with the acidic Triton X-100 solution. The sample was centrifuged until the emulsion breaking. After the emulsion breaking, two well-separated phases were formed. The acidic aqueous phase was diluted to the calibrated volume and then the determination was achieved using either F-AAS or ICPOES.

\section{References:}

1. McElroy, F., et al., Uses and applications of inductively coupled plasma mass spectrometry in the petrochemical industry. Spectroscopy, 1998. 13(2): p. 42-+.

2. B.Y, C., PCA: The Basic Building Block of Chemometrics. 2012.

3. Souza, R.M., C.L.P. da SILVEIRA, and R.Q. Aucelio, Determination of refractory elements in used oil by ICPOES employing emulsified sample introduction and calibration with inorganic standards. Analytical sciences, 2004. 20(2): p. 351-355.

4. Yawar, W., Determination of wear metals in lube oils by flame atomic absorption spectrophotometry. Journal of Analytical Chemistry, 2010. 65(5): p. 489-491.

5. Salvador, A., M. de La Guardia, and V. Berenguer, Determination of the total iron content of used lubricating oils by atomic-absorption with use of emulsions. Talanta, 1983. 30(12): p. 986-988.

6. Barbooti, M.M., et al., Use of silica gel in the preparation of used lubricating oil samples for the determination of wear metals by flame atomic absorption spectrometry. Analyst, 1990. 115(8): p. 1059-1061.

7. Bellido-Milla, D., et al., Rapid procedure to determine wear metals in lubricating oils and the analysis of variance in the evaluation of sample preparation procedures. Microchimica Acta, 2002. 138(1-2): p. 59-64.

8. Costa, L.M., et al., Use of factorial design for optimization of microwave-assisted digestion of lube oil. Jurnal of the Brazilian Chemical Society, 2005. 16(6A): p. 12691274.

9. Vahaoja, P., et al., Determination of wear metals in lubrication oils: a comparison study of ICP-OES and FAAS. Analytical sciences, 2005. 21(11): p. 1365-1369.

10. Brown, R.J., Determination of trace metals in petroleum and petroleum products using an inductively coupled plasma optical emission spectrometer. Spectrochimica Acta Part B: Atomic Spectroscopy, 1983. 38(1-2): p. 283-289.

11. Aucélio, R.Q., A.J. Curtius, and B. Welz, Sequential determination of Sb and Sn in used lubricating oil by electrothermal atomic absorption spectrometry using $R u$ as a permanent modifier and microemulsion sample introduction. Journal of Analytical Atomic Spectrometry, 2000. 15(10): p. 1389-1393. 
12. Saba, C.S. and K.J. Eisentraut, Determination of molybdenum wear metal in lubricating oils by atomic absorption spectrophotometry with a particle size independent method. Analytical Chemistry, 1979. 51(12): p. 1927-1930.

13. Burguera, J.L. and M. Burguera, Analytical applications of emulsions and microemulsions. Talanta, 2012. 96: p. 11-20.

14. Leite, C.C., et al., Determination of $\mathrm{Fe}, \mathrm{Cr}$ and $\mathrm{Cu}$ in used lubricating oils by ET AAS using a microemulsion process for sample preparation. Analytical Methods, 2015. 7(8): p. 3363-3371.

15. Ahmad, H., et al., determination of wear elements in tractor oil: comparison between aas and icp-oes techniques. Nigerian institution of agricultural engineers, 2014. 22(1): p. 19.

16. CHEN, Z.-j., et al., Determination of Metals in Lubricating Oil with Domestic ICP-AES [J]. Guangzhou Chemical Industry, 2010. 4: p. 049.

17. Marume, C., Elemental determination of lubricating grease using ICP-OES. 2015.

18. Duyck, C., et al., Trace element determination in crude oil and its fractions by inductively coupled plasma mass spectrometry using ultrasonic nebulization of toluene solutions. Spectrochimica Acta Part B: Atomic Spectroscopy, 2002. 57(12): p. 19791990. 